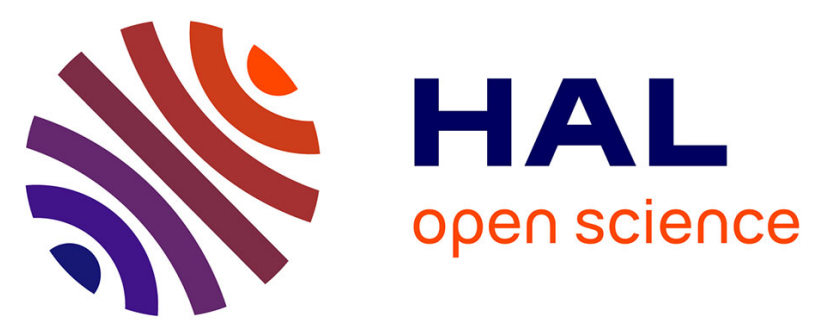

\title{
Corticotropin-releasing hormone effects on human pregnant vs. nonpregnant myometrium explants estimated from a mathematical model of uterine contraction.
}

T.M. Mignot, Bruno Paris, Benjamin Carbonne, C. Vauge, Frédéric Ferre, Daniel Vaiman

\section{To cite this version:}

T.M. Mignot, Bruno Paris, Benjamin Carbonne, C. Vauge, Frédéric Ferre, et al.. Corticotropinreleasing hormone effects on human pregnant vs. nonpregnant myometrium explants estimated from a mathematical model of uterine contraction.. Journal of Applied Physiology, 2005, 99, pp.1157-1163. hal-02675678

\author{
HAL Id: hal-02675678 \\ https://hal.inrae.fr/hal-02675678
}

Submitted on 31 May 2020

HAL is a multi-disciplinary open access archive for the deposit and dissemination of scientific research documents, whether they are published or not. The documents may come from teaching and research institutions in France or abroad, or from public or private research centers.
L'archive ouverte pluridisciplinaire HAL, est destinée au dépôt et à la diffusion de documents scientifiques de niveau recherche, publiés ou non, émanant des établissements d'enseignement et de recherche français ou étrangers, des laboratoires publics ou privés. 


\title{
Corticotropin-releasing hormone effects on human pregnant vs. nonpregnant myometrium explants estimated from a mathematical model of
} uterine contraction

\author{
Thérèse-Marie Mignot, ${ }^{1}$ Brigitte Paris, ${ }^{1}$ Bruno Carbonne, ${ }^{1,2}$ \\ Christian Vauge, ${ }^{\mathbf{1}}$ Françoise Ferré, ${ }^{\mathbf{1}}$ and Daniel Vaiman ${ }^{1}$ \\ ${ }^{1}$ Génétique et Epigénétique des Pathologies Placentaires, Institut National de la Santé et de la Recherche \\ Médicale U. 709, IFR Alfred Jost, Université René Descartes Paris V, ${ }^{2}$ Service de Gynécologie-Obstétrique \\ Hôpital Saint-Antoine, and Département de Génetique Animale, INRA Paris, France
}

Submitted 8 February 2005; accepted in final form 26 April 2005

\begin{abstract}
Mignot, Thérèse-Marie, Brigitte Paris, Bruno Carbonne, Christian Vauge, Françoise Ferré, and Daniel Vaiman. Corticotropin-releasing hormone effects on human pregnant vs. nonpregnant myometrium explants estimated from a mathematical model of uterine contraction. J Appl Physiol 99: 1157-1163, 2005. First published April 28, 2005; doi:10.1152/japplphysiol.00158.2005.-In this paper, we applied a new theoretical model of uterine contraction to a large panel of human pregnant and nonpregnant myometrial strips, treated or not by corticotrophin-releasing hormone (CRH). This model is based on a fine analysis of the contraction curves. This analysis yielded four mathematical parameters (beta, theta, tau 1, and tau 2) related to excitability, duration of plateau phase, and time constants for relaxation describing, respectively, the different portions of the contraction cycle. This leads to specific differences in spontaneous contractile activity between pregnant and nonpregnant states. The relaxing effect of $\mathrm{CRH}$ in the pregnant state is presumably correlated with the origin of the strips (the lower uterine segment). Besides our observation of a specific receptor-dependent relaxing effect of $\mathrm{CRH}$ in both pregnant and nonpregnant myometrium, we could identify highly significant effects at given $\mathrm{CRH}$ concentration for beta in nonpregnant myometrium and for theta, tau 1 , and tau 2 in pregnant myometrium. In addition, highly significant differences were found between pregnant and nonpregnant myometrium. Also, we discovered a strong correlation between theta and tau 1 , specifically in the pregnant state. Although the biochemical signification of these results remains to be elucidated, they contribute to emphasize the complex network of $\mathrm{CRH}$ action at the myometrial level. Furthermore, our approach could pave the way toward a better analysis of the efficacy of the uterine contractile behavior.
\end{abstract}

myometrium; pregnancy; contraction; mathematical modeling

CORTICOTROPHIN-RELEASING HORMONE (CRH), a 41-amino acid neuropeptide, was first isolated from ovine hypothalamus (27). In humans, the exponential rise in maternal plasma $\mathrm{CRH}$ between the second trimester of pregnancy and term and the further increase during labor have been attributed to synthesis by gestational tissues (17). On the basis of these data, it was hypothesized that placental CRH production, which controls fetal maturation, is also linked to the length of human gestation $(2,15,16)$. CRH receptors have been identified within almost every tissue at the feto-maternal interface, and it was reported that, at this site, $\mathrm{CRH}$, acting in a paracrine/autocrine fashion

Address for reprint requests and other correspondence: D. Vaiman, Génétique et Epigénétique des Pathologies Placentaires INSERM U. 709, IFR Alfred Jost, Université René Descartes Paris V, Pavillon Baudelocque, 123 Boulevard de Port-Royal 75014, Paris, France (E-mail address: vaiman@cochin.inserm.fr). with several other signaling factors such as proinflammatory cytokines and prostaglandins, contributes to the integrative processes involved in the onset of labor $(4,8,18,20,22,25)$. Consequently, the human myometrium can be viewed as the final target of $\mathrm{CRH}$ action on uterine contractile activity. However, the identification of multiple specific CRH receptor isoforms in the myometrium $(6,14)$ raises the question of a direct action of the peptide $(8,11)$. Because the expression and biological activity of several of these receptor isoforms change during pregnancy and with labor, a physiological, receptorbased switch from relaxation to contractility was hypothesized at the time of parturition (7).

In parallel with these studies, which explore the $\mathrm{CRH}$ signaling pathways, other experiments investigated the effects of $\mathrm{CRH}$ on contractility of myometrial strips obtained from term pregnant women before the onset of labor. Quartero et al. (21) found that the $\mathrm{CRH}$ potentiation of the contractile effect of oxytocin is mediated by PGF2 $\alpha$. Consistently, Benedetto et al. (1) have confirmed that CRH enhances the myometrial sensitivity to PGF2 $\alpha$. By contrast, in another study, the contractile responses to oxytocin and PGE2 $\alpha$ were not modified by CRH (24). These contradictory data have been attributed to different experimental protocols for the measurement of myometrial activity. Furthermore, Petraglia and coworkers have shown that the CRH binding protein may play a regulatory action in inhibiting the contractile activity mediated by the combination of CRH and PGF2 $\alpha$ (20). All these studies failed to demonstrate any significant effect when CRH was added alone.

In the present study, we compare nonpregnant and pregnant women close to term for in vitro $\mathrm{CRH}$ myometrial responsiveness, according to a mathematical model established previously to describe uterine contractile activity during human parturition (28). This model was recently applied to the analysis of spontaneous contractions in myometrial strips obtained from nonpregnant women (29). It is based on simulations of the contraction curve, with the estimation of four specific mathematical parameters. We developed software that enables researchers to automatize their calculation. Several of these parameters reveal highly significant differences between pregnant and nonpregnant myometrium as well as in their response to $\mathrm{CRH}$. Furthermore, we observe that these parameters are differently affected by varying CRH concentrations.

The costs of publication of this article were defrayed in part by the payment of page charges. The article must therefore be hereby marked "advertisement" in accordance with 18 U.S.C. Section 1734 solely to indicate this fact. 


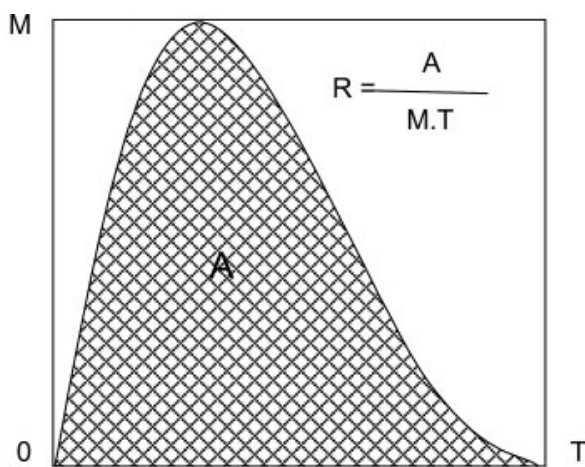

\section{tension (g)}

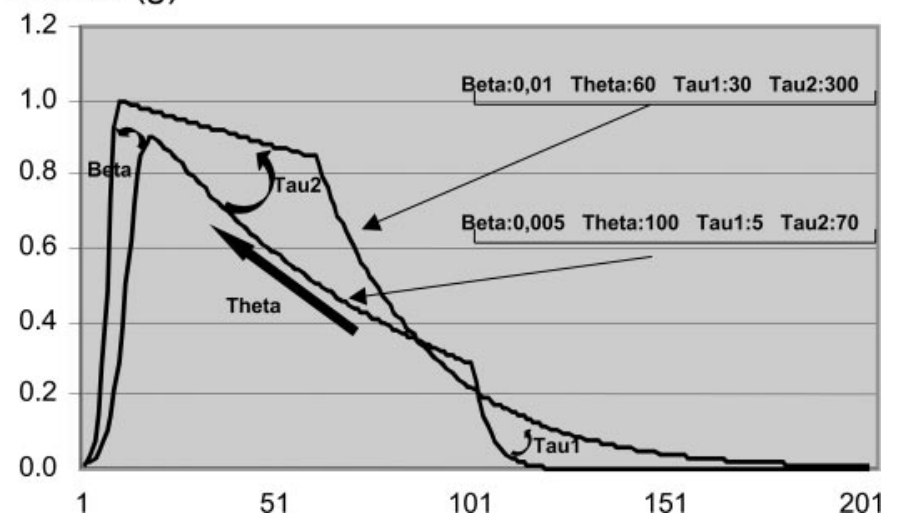

Fig. 1. Top: definition of the $\mathrm{R}$ parameter. $\mathrm{R}$ is defined as the ratio of the area of the contraction curve (A) by the area of the minimal rectangle encompassing the curve (M.T). Bottom: simulation of typical isometric contractions according to the nonlinear 4-parameter model previously described (29). Beta $\left(\mathrm{s}^{-1}\right)$ is representative of the slope of the curve in the initial phase of the contraction and, therefore, of the excitability of the myometrial strip analyzed. Theta, tau 1 , and tau 2 influence the duration of the contraction: Theta (s) represents the length (duration) of the plateau. Tau 2 (s) and tau 1 (s) influence the time necessary for relaxing the myometrial strip by playing on the angles of the plateau (tau 2) and the angle of return to baseline after the plateau (tau 1). Therefore, both are time constants of the exponential decay regimen of the plateau and relaxation phase, respectively. To summarize, beta represents the number of cells that the strip is able to mobilize when the contraction impulse is given, whereas the 3 other parameters are indicative of the number of cells able to stay in a contracted state after the primary excitation. Two theoretical curves are presented on the figure and are representative of extreme situations of the model.

\section{MATERIALS AND METHODS}

Biological samples. Human myometrial tissue was obtained from 19 cycling women $(41.3 \pm 11.1 \mathrm{yr}$ old $)$ undergoing hysterectomy for benign gynecological indications such as leiomyomas. None of the patients was under hormonal treatment at the time of surgery. Tissue samples were excised in the uterine corpus from normal muscle in areas free of macroscopically visible anomalies. Myometrial tissue was also taken from 13 women with normal uncomplicated pregnancies $(35.9 \pm 4.8 \mathrm{yr}$ old $)$. They were delivered by elective caesarean section performed outside the onset of labor, between weeks 36 and 40 of pregnancy, indicated for diagnosed cephalopelvic disproportion or previous caesarean sections. Tissue samples were collected in the uterine corpus between the lower segment and the fundus as much as possible in similar sites as in nonpregnant women. This study was approved by the Cochin Hospital Ethics Committee (Comité Consultatif pour la Protection des Personnes dans la Recherche Biomédicale), and patients gave written, informed consent. All myometrial samples were taken in the external longitudinal layer. They were dissected free of serosa and immediately placed in physiological saline solution (29) with the following concentrations (in $\mathrm{mM}$ ): 6.2 $\mathrm{KCl}, 144 \mathrm{NaCl}, 2.5 \mathrm{CaCl}_{2}, 0.5 \mathrm{MgCl}_{2}, 1 \mathrm{NaH}_{2} \mathrm{PO}_{4}, 30 \mathrm{NaHCO}_{3}$, and 11.1 glucose.

Tissue bath experiments. Studies were performed with myometrial strips ( 5 to $7 \times 2 \times 1 \mathrm{~mm}$ ) suspended in a 6-ml organ bath containing the physiological salt solution at $32^{\circ} \mathrm{C}, \mathrm{pH} 7.4$, bubbled with a gas mixture $\left(95 \% \mathrm{O}_{2}-5 \% \mathrm{CO}_{2}\right)$. Contractile activity was measured isometrically using a Pioden F1 tension transducer (Phymep, Paris, France), followed by computerized recording and processing (Analog Digital Instruments). The preparations were allowed to equilibrate for $2 \mathrm{~h}$ under a static tension of $0.8 \mathrm{~g}(7.8 \mathrm{mN})$, and the physiological salt solution in the tissue baths was changed every $20 \mathrm{~min}$. Any muscle strip that did not develop spontaneous contractions, regular in frequency and strength at the end of equilibration period, was discarded. Overall, $84 \%$ of the strips yielded spontaneous contractions $(64 \%$ for strips from pregnant patients and $98 \%$ from strips obtained from nonpregnant patients). After equilibration, spontaneously active tissue was exposed every $20 \mathrm{~min}$ to a cumulative increase in concentrations of human/rat CRH (Neosystem, Strasbourg, France) from $10^{-10}$ to $10^{-6} \mathrm{M}$. Another set of experiments was performed to exclude nonspecific action of the peptide. $\mathrm{CRH}$ receptor antagonists antisauvagine (for R2 receptor subtypes) or astressin [acting on both R1 (3) and $\mathrm{R} 2$ receptor (13) subtypes; Neosystem] were added at $2 \times 10^{-6}$ M $50 \mathrm{~min}$ before the strips were incubated with $10^{-7} \mathrm{M} \mathrm{CRH}$.

Table 1. Variation coefficients (SD/mean) and range for the 4 calculated parameters for spontaneous contractions and at various CRH concentrations

\begin{tabular}{|c|c|c|c|c|}
\hline & Pregnant & Range & Nonpregnant & Range \\
\hline \multicolumn{5}{|c|}{ Beta } \\
\hline $\mathrm{SC}$ & 0.43 & $0.09-0.66$ & 0.56 & $0.00-1.12$ \\
\hline CRH-10 & 0.4 & $0.00-0.98$ & 0.59 & $0.00-1.53$ \\
\hline CRH-9 & 0.55 & $0.00-2.30$ & 0.59 & $0.00-1.51$ \\
\hline CRH-8 & 0.47 & $0.00-1.03$ & 0.99 & $0.00-1.28$ \\
\hline CRH-7 & 0.31 & $0.00-0.83$ & 0.96 & $0.00-1.51$ \\
\hline CRH-6 & 0.19 & $0.00-0.99$ & 0.53 & $0.00-1.03$ \\
\hline \multicolumn{5}{|c|}{ Theta } \\
\hline $\mathrm{SC}$ & 0.23 & $0.00-0.88$ & 0.19 & $0.00-0.39$ \\
\hline CRH-10 & 0.34 & $0.00-0.99$ & 0.15 & $0.00-0.42$ \\
\hline CRH-9 & 0.16 & $0.00-0.35$ & 0.17 & $0.00-0.44$ \\
\hline CRH-8 & 0.28 & $0.00-0.65$ & 0.39 & $0.00-2.00$ \\
\hline CRH-7 & 0.21 & $0.00-0.47$ & 0.37 & $0.00-1.75$ \\
\hline CRH-6 & 0.11 & $0.00-0.60$ & 0.16 & $0.00-0.31$ \\
\hline \multicolumn{5}{|c|}{ Таи 1} \\
\hline $\mathrm{SC}$ & 0.32 & $0.00-0.56$ & 0.34 & $0.00-0.68$ \\
\hline CRH-10 & 0.25 & $0.00-0.64$ & 0.21 & $0.00-0.49$ \\
\hline CRH-9 & 0.25 & $0.00-0.76$ & 0.23 & $0.00-0.70$ \\
\hline CRH-8 & 0.24 & $0.00-0.55$ & 0.36 & $0.00-1.00$ \\
\hline CRH-7 & 0.19 & $0.00-0.67$ & 0.38 & $0.00-1.60$ \\
\hline CRH-6 & 0.07 & $0.00-0.72$ & 0.33 & $0.00-0.54$ \\
\hline \multicolumn{5}{|c|}{ Tаи 2} \\
\hline $\mathrm{SC}$ & 0.69 & $0.00-1.23$ & 0.75 & $0.00-1.37$ \\
\hline CRH-10 & 0.59 & $0.00-1.59$ & 0.64 & $0.00-1.09$ \\
\hline CRH-9 & 0.74 & $0.00-2.68$ & 0.79 & $0.00-1.57$ \\
\hline CRH-8 & 0.69 & $0.00-1.63$ & 0.43 & $0.00-1.06$ \\
\hline CRH-7 & 0.76 & $0.00-1.67$ & 0.68 & $0.00-1.24$ \\
\hline CRH-6 & 0.56 & $0.00-1.53$ & 0.61 & $0.00-1.74$ \\
\hline
\end{tabular}

CRH, corticotrophin-releasing hormone; beta, slope of the curve in the initial phase of contraction; theta, length (duration) of the plateau; tau 1, time necessary for relaxing myometrial strip by playing in the angle of return to base line after plateau; tau 2, time necessary for relaxing myometrial strip by playing on the angle of the plateau. SC, spontaneous contractions. 
A

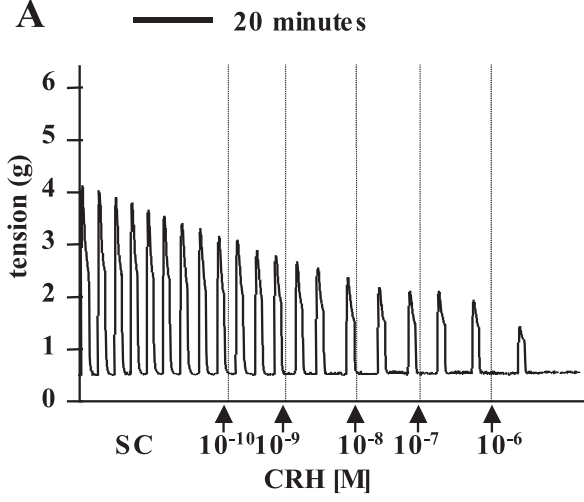

20 minutes

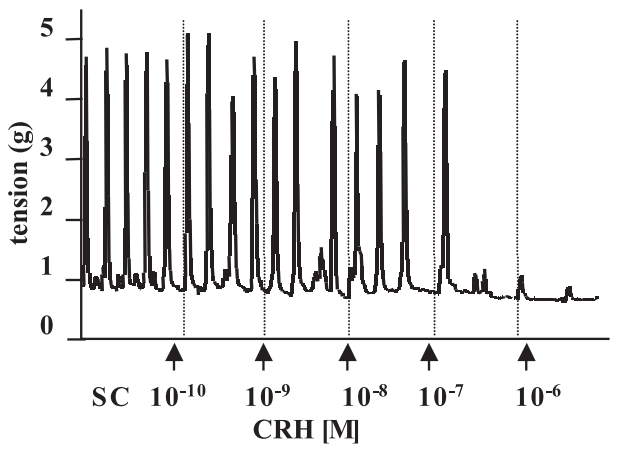

B $\longrightarrow 20$ minutes

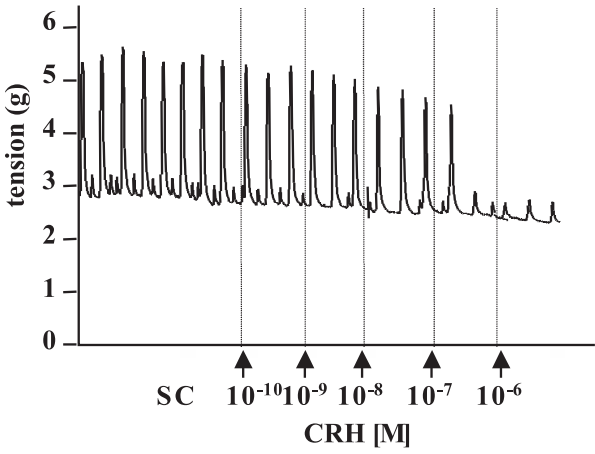

20 minutes

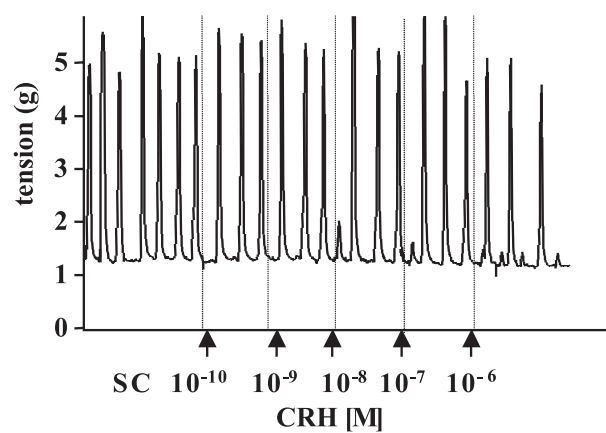

Fig. 2. Effects of cumulative addition of corticotrophin-releasing hormone $(\mathrm{CRH})$ on spontaneous contractions (SC) in longitudinal myometrial strips from 2 nonpregnant $(A)$ and 2 pregnant women $(B)$
Exposure of control strips to vehicle alone $(30 \mu l$ of physiological salt solution) without or with antagonists did not alter spontaneous contractions. The effect of $\mathrm{K}^{+}$depolarization $(50 \mathrm{mM} \mathrm{KCl})$ was recorded at the end of each experiment, confirming the sample viability.

Mathematical model and data analysis. We define R, a parameter which measures the relative energy of the contraction as previously described by Vauge et al. (29). It corresponds to the ratio between the contraction curve area and the area of the minimal rectangle encompassing the curve (Fig. 1, top). Therefore, it is a dimensionless parameter, ranging between 0 and $100 \%$, quantifying the relative energy of the actual contraction compared with a theoretical contraction of maximal duration and intensity. Four parameters characterized the actual shape of the contraction, and their effect is presented by two theoretical curves (not obtained from the actual data) showing extreme effects of varying the four parameters (Fig. 1, bottom). Their signification can be summarized in the following way. Beta is related to the slope of the initial phase of the contraction. Theta corresponds to the duration of the plateau following this initial phase. Tau 1 is the time necessary for bringing the contraction to baseline, close to 0 when the drop is immediate and increasing when the decay is less steep. Tau 2 represents the slope of the plateau, i.e., when its value is above $10 \mathrm{~s}$, the plateau is almost horizontal.
For automated calculations of the four parameters of the theoretical contraction curve, an Excel macro was developed in Visual Basic and is available from the authors on request. The program input is constituted of a sheet called "Patients," where the number of curves studied is specified and where the ordinates of each curve are entered in consecutive columns. The main calculation sheet is composed of two sets of 1,600 rows containing the number of contracted cells and the total number of available cells, these two values participating in the calculation, and this at each second for the $200 \mathrm{~s}$ from the beginning of the contraction. Each of the 1,600 pairs of rows of the sheet contains the parameter of one curve, with 10 possible values of theta from 10 to $185(10,20,30,40,60,70,80,90,110,185), 10$ possible values of tau 1 from 5 to $50(5,10,12,14,16,18,20,25,37$, $50)$, and 16 possible values of tau $2(12,40,60,75,87,95,110,125$, $140,155,170,185,200,500,1,000,2,000)$. The macro then performs iterations on the value of beta from 0 to $10^{-2}$ by recursive iterations beginning with $5 \times 10^{-5}$ and ending at $5 \times 10^{-6}$. The theoretical curve was compared with the empirical curve by a standard minimization of the least squares for each set of theta, tau 1, and tau 2 between the empirical and theoretical value calculated at each time from 0 to $200 \mathrm{~s}$ for a given value of beta. The optimal curve among the 1,600 calculations was then stored, and the procedure resumed

Table 2. Summary of the contractions analyzed

\begin{tabular}{|c|c|c|c|c|c|c|c|c|c|c|}
\hline Nonpregnant & Spontaneous & CRH-10 & CRH-9 & CRH $310-9$ & CRH-8 & CRH $310-8$ & CRH-7 & CRH 3 10-7 & CRH-6 & Total \\
\hline Patients & 19 & 12 & 13 & 1 & 14 & 1 & 12 & 4 & 8 & \\
\hline Explants & 35 & 21 & 22 & 2 & 24 & 2 & 24 & 5 & 13 & \\
\hline Curves & 252 & 63 & 70 & 2 & 89 & 3 & 82 & 9 & 39 & 609 \\
\hline Pregnant & Spontaneous & CRH-11 & CRH-10 & CRH 10-9 & CRH-8 & CRH 3 10-8 & CRH-7 & CRH 3 10-7 & CRH-6 & \\
\hline Patients & 13 & 2 & 7 & 8 & 9 & 3 & 12 & 4 & 10 & \\
\hline Explants & 22 & 3 & 12 & 13 & 13 & 6 & 16 & 5 & 15 & \\
\hline Curves & 156 & 8 & 30 & 35 & 36 & 17 & 77 & 11 & 61 & 431 \\
\hline
\end{tabular}




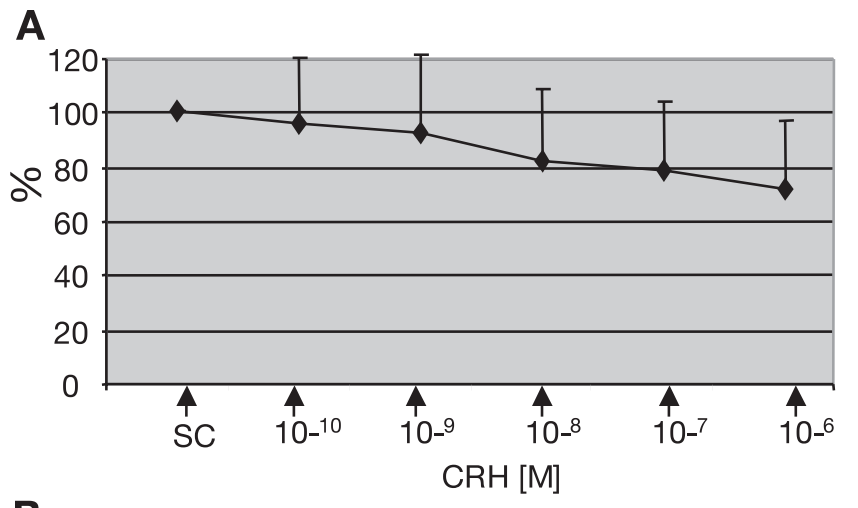

B

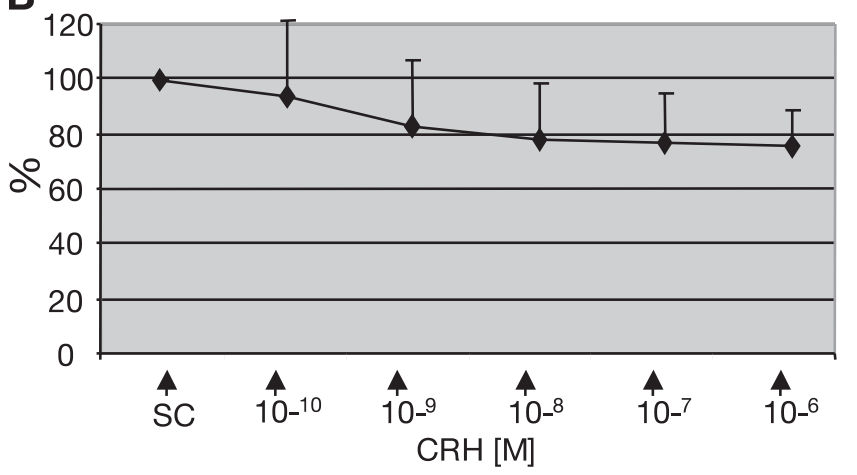

Fig. 3. Variations of $\mathrm{R}$ according to increasing $\mathrm{CRH}$ concentrations in nonpregnant $(A)$ and pregnant $(B)$ myometrium. The average value of $\mathrm{R}$ for the complete set of SC was used to set a reference maximum at $100 \%$ arbitrary units. Means are shown with bars indicating SD.

with the next value of beta. The program follows the evolution of the sum of square differences when beta varies until it finds a minimum, which is then kept as the optimal curve for the four parameters. The result file is stored in one of the Excel sheets (patient results). With a standard laptop computer (2-GHz processor), 250 curve parameters can be calculated in $<2 \mathrm{~h}$.

Statistics. After automatic calculations of the four parameters, the various curves obtained from each patient and each CRH concentration were averaged, and the interindividual variation was computed (Table 1) by estimating the variation coefficients (standard deviation/ mean). The values of $\mathrm{R}$, beta, theta, tau 1 , and tau 2 obtained for various concentrations of $\mathrm{CRH}$ were systematically compared using one-factor ANOVA for pregnant as well as nonpregnant myometrial contraction curves. The effects of each concentration of $\mathrm{CRH}$ were compared between pregnant and nonpregnant myometrial contraction curves using a Student's two-tailed $t$-test with variances supposed equal (homoskedastic $t$-test).
Table 4. Student's tests comparing the effects of CRH concentrations on each parameter of the contraction curve between pregnant and nonpregnant patients

\begin{tabular}{|c|c|c|c|c|c|c|}
\hline \multirow{2}{*}{\multicolumn{2}{|c|}{$\begin{array}{l}\text { Spontaneous } \\
\text { Contractions }\end{array}$}} & \multicolumn{5}{|c|}{$\mathrm{CRH}, \mathrm{M}$} \\
\hline & & $10^{-10}$ & $10^{-9}$ & $10^{-8}$ & $10^{-7}$ & $10^{-6}$ \\
\hline Beta & 0.2394 & 0.4184 & 0.6964 & 0.0973 & 0.0288 & $6.0559 \times 10^{-4}$ \\
\hline Theta & $1,2759 \times 10^{-5}$ & 0.2181 & 0.0457 & 0.0214 & $9.4183 \times 10^{-9}$ & $1.1033 \times 10^{-6}$ \\
\hline Tau 1 & 0.0048 & 0.0152 & 0.0008 & 0.1309 & 0.8934 & 0.5335 \\
\hline Tau 2 & $22.2722 \times 10^{-4}$ & 0.0836 & 0.1627 & 0.2193 & 0.7774 & 0.8841 \\
\hline
\end{tabular}

\section{RESULTS}

Overall in vitro effects of $\mathrm{CRH}$ on the myometrial spontaneous contractions in pregnant and nonpregnant states. The effects of cumulative application of $\mathrm{CRH}$ are illustrated by four examples of contraction profiles (Fig. 2). Clearly, CRH has a dose-dependent relaxing action in nonpregnant and pregnant myometrium. When contractions were suppressed with $10^{-7}$ $\mathrm{M} \mathrm{CRH}$, this effect is completely blocked by preincubation with $2 \times 10^{-6} \mathrm{M}$ astressin, whereas the inhibitory effect of antisauvagine at the same concentration was only partial (data not shown). Although the specificity of these antagonists is only partial, these results suggest that, in our experiments, the $\mathrm{R} 1$ receptor is preferentially involved in the response to $\mathrm{CRH}$. Whereas no change was induced by $\mathrm{CRH}$ in the basal tone of the contractions, we noticed a clear variability between individuals both in nonpregnant and pregnant states on others parameters such as frequency or amplitude (Fig. 2). Therefore, the relaxing effect of $\mathrm{CRH}$ was not systematically observed when only one parameter was taken into account. To overcome this individual variability of $\mathrm{CRH}$ effects on uterine contractile activity, we switched to a more sensitive approach.

$C R H$ effects on the contractions analyzed by the $R$ parameter variations. $\mathrm{R}$ values were calculated from 553 curves from 35 myometrial strips obtained from 19 nonpregnant women and 342 curves from 22 myometrial strips obtained from 13 pregnant women (Table 2$)$. Higher $\mathrm{R}$ values were found $(P=$ $\left.9 \times 10^{-5}\right)$ for spontaneous contractions in nonpregnant states $(0.23 \pm 0.07)$ compared with pregnant $(0.13 \pm 0.05)$. In both cases, to test the $\mathrm{CRH}$ effect, the reference value of $\mathrm{R}$ was set at $100 \%$ for spontaneous contractions (Fig. 3). For nonpregnant myometrium, the $\mathrm{CRH}$ displayed clearly a dose-dependent relaxing effect. However, this effect was significant only from a concentration of $10^{-8} \mathrm{M}$ (compared with spontaneous contractions, $P=4.5 \times 10^{-3}$ ), as well as with any other higher

Table 3. Average values of the 4 parameters defining the contraction curve

\begin{tabular}{|c|c|c|c|c|c|c|c|c|c|}
\hline \multicolumn{5}{|c|}{ Nonpregnant Women } & \multicolumn{5}{|c|}{ Pregnant Women } \\
\hline & Beta & Theta & Tau 1 & Tau 2 & & Beta & Theta & Tau 1 & Tau 2 \\
\hline Spontaneous & 0.000665 & 65 & 15.4 & 376 & Spontaneous & 0.000560 & 47 & 18.9 & 606 \\
\hline $10^{-10}$ & 0.000827 & 55 & 14.3 & 521 & $10^{-11}$ & 0.000319 & 50 & 20.6 & 424 \\
\hline $10^{-9}$ & 0.000830 & 67 & 14.1 & 485 & $10^{-10}$ & 0.000638 & 47 & 20.0 & 318 \\
\hline $3 \cdot 10^{-9}$ & 0.001375 & 48 & 14.0 & 365 & $10^{-9}$ & 0.000759 & 50 & 21.8 & 321 \\
\hline $10^{-8}$ & 0.000897 & 61 & 15.3 & 463 & $10^{-8}$ & 0.000500 & 45 & 18.5 & 604 \\
\hline $3 \cdot 10^{-8}$ & 0.001750 & 51 & 11.7 & 298 & $3 \cdot 10^{-8}$ & 0.000867 & 48 & 20.3 & 580 \\
\hline $10^{-7}$ & 0.001034 & 71 & 14.4 & 359 & $10^{-7}$ & 0.000606 & 37 & 14.6 & 379 \\
\hline $3 \cdot 10^{-7}$ & 0.001212 & 81 & 13.3 & 315 & $3 \cdot 10^{-7}$ & 0.001730 & 59 & 26.5 & 548 \\
\hline $10^{-6}$ & 0.001598 & 58 & 14.3 & 361 & $10^{-6}$ & 0.000575 & 36 & 15.6 & 348 \\
\hline
\end{tabular}



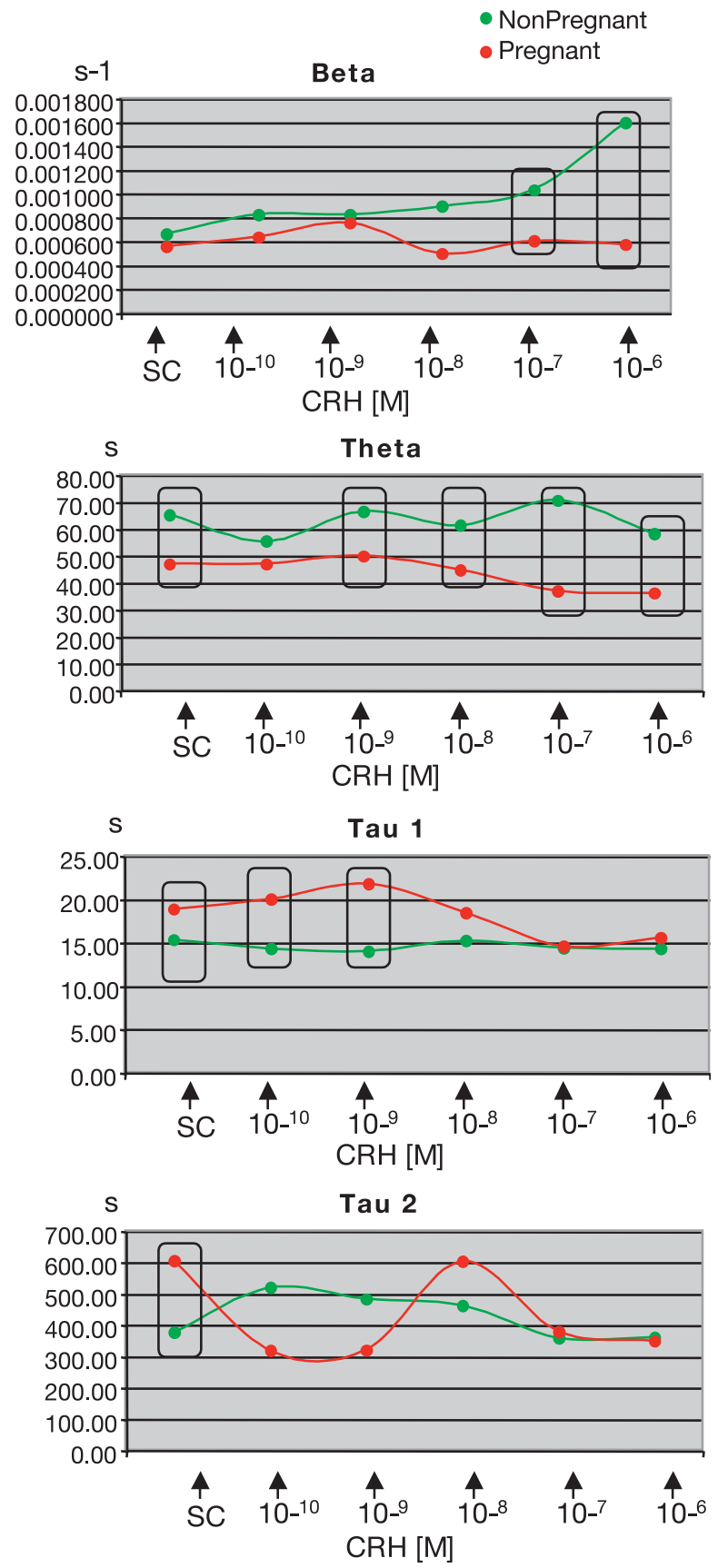

Fig. 4. Variations of the 4 parameters beta, theta, tau 1 , and tau 2 in nonpregnant (green circles) or pregnant (red circles) myometrium according to increasing $\mathrm{CRH}$ concentrations. Statistical significance was evaluated for each CRH concentration between pregnant and nonpregnant curves by Student's $t$-test and presented in an open box when found significant.

concentrations. We could similarly demonstrate a significant relaxing effect of $\mathrm{CRH}$ in pregnant myometrium from $10^{-9} \mathrm{M}$ $\mathrm{CRH}\left(P=2.5 \times 10^{-3}\right)$ to each higher concentration.

CRH effects on the different phases of the uterine contraction shape. Average values of beta, theta, tau 1, and tau 2 were also computed from the same curves as for $\mathrm{R}$ calculation (Table 3). Interestingly, we observed that the interpatient variability of the parameters displays a clear tendency to decrease with increasing CRH concentration only for pregnant myometria, suggesting a trend toward a better organization of the contractile response (Table 1). One-factor ANOVA was performed for each parameter in both situations and made it possible to detect a significant effect of $\mathrm{CRH}$ on beta in nonpregnant contractions only $\left(P=6.9 \times 10^{-3}\right)$, with beta increasing steadily with CRH concentrations (Table 4 and Fig. 4). By contrast, highly significant effects were distinguishable for theta $\left(P<0.2 \times 10^{-4}\right)$, tau $1\left(P<0.3 \times 10^{-4}\right)$, and tau $2\left(P=1.8 \times 10^{-2}\right)$, but only in pregnant myometrium where theta and tau 1 tend to decrease when CRH concentration is raised. The evolution of tau 2 appears much more complex, with a decrease of $50 \%$ at $10^{-10}$ and $10^{-9} \mathrm{M} \mathrm{CRH}$. Around $10^{-8} \mathrm{M} \mathrm{CRH}$, tau 2 is reset to spontaneous contraction values, then decreases again to $\sim 50 \%$ at higher concentrations.

To compare the curve parameters between pregnant and nonpregnant myometrium, we performed a Student's $t$-test analysis between the two categories for spontaneous contractions and for each CRH concentration where data were available (Table 4). Figure 4 shows that, in the case of spontaneous contractions, no difference in beta was observed between nonpregnant and pregnant states. By contrast, in nonpregnant, theta was significantly higher, whereas tau 1 and tau 2 were significantly lower than in pregnant state. When CRH was applied, beta became significantly different only for high concentrations of the peptide (from $10^{-7} \mathrm{M}$ ). It appears that, in these cases, beta was about twice higher in nonpregnant than in pregnant myometrium. As was observed with spontaneous contractions, theta remained significantly increased in nonpregnant myometrium for almost all the $\mathrm{CRH}$ concentrations. Tau 1 remained significantly higher in pregnant myometrium, but only for low CRH concentrations. Finally, Tau 2 presented a more chaotic distribution, where no significant difference was found between nonpregnant and pregnant states.

In our results, the most striking observation may be the strong correlation observed between the two parameters theta and tau 1 ( $r=\sim 0.98)$, but only in pregnant myometrium, whereas the correlation coefficient was only 0.19 in nonpregnant myometrium (Fig. 5).

\section{DISCUSSION}

In this paper, we present an enhanced way of analyzing the contractility of the uterus, which relies not merely on the

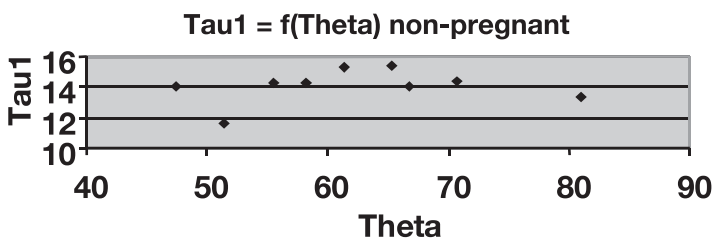

Tau1 $=f($ Theta $)$ pregnant

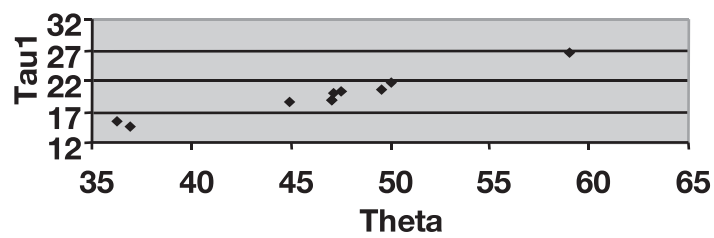

Fig. 5. Correlations between tau 1 and theta for nonpregnant (top) and pregnant (bottom) myometrial contraction curves, according to increasing $\mathrm{CRH}$ concentrations. The correlation is very high (0.98) only in pregnant myometrium (see text). 
energetic efficiency $(\mathrm{R})$ of the contraction but also on the specific shape of this contraction, evaluated by four specific parameters. We compared systematically the effects of various $\mathrm{CRH}$ concentrations on spontaneous myometrial contractility in both pregnant and nonpregnant uteri. $\mathrm{R}$ is significantly higher in nonpregnant women suggesting that, in pregnant outside the labor, efficient contractions are prevented. In addition, we demonstrate relaxing effects of CRH in both pregnant and nonpregnant myometrium, albeit higher concentrations were necessary to observe a difference in nonpregnant uteri. This is consistent with the documented higher affinity of myometrial CRH receptors in pregnant women near term (9). One important follow up of this study will be the analysis by quantitative RT PCR and immunohistochemistry of the distribution of the $\mathrm{CRH}$ receptors in the myometrium.

Our decomposition of CRH effects into four parameters is suggestive of highly complex regulatory mechanisms, dependent on the peptide concentration as well as gestation state. Our data may be related to a new endocrinological equilibrium near term with a different pattern of CRH receptor expression (6, $10,14)$. Due to activation of PKC by oxytocin, CRH receptor binding affinity for CRH and activation of adenylate cyclase are reduced in pregnant term but not in pregnant preterm myometrium, which endorses a shift toward contractility rather than relaxation (7). In addition, time-scheduled shifts in the main CRH receptor subtypes may also explicate the complexity of CRH regulation of uterine contraction. Several G protein-coupled CRH receptor subtypes have been characterized inside the two distinct classes, R1 and R2, differing by binding affinities for CRH and CRH-related peptides: CRH binds R1 receptors with a higher affinity than $\mathrm{R} 2$ receptors $(6,11,23)$. At $10^{-7} \mathrm{M} \mathrm{CRH}$, the partial inhibition observed in our hands with antisauvagine and the complete inhibition with astressin, although probably not completely specific, are consistent with the activation of certain R1 and R2 receptor subtypes implicated in the relaxation process via the cAMP pathway (7). It is possible that the inability of $\mathrm{CRH}$ to increase myometrial contractility in the pregnant state is due to the fact that patients are not in labor or to the proximity of our samples to the lower segment (26). However, our findings showing differential effect in some parameters values depending on CRH concentrations suggest that the activation of additional signaling pathways is not excluded (19) even if the overall effect of the peptide was relaxation. Indeed, a dual role (maintenance of myometrial relaxation and stimulation of contractility by $\mathrm{CRH}$ and CRH related peptides) is proposed during pregnancy and labor $(8,12,26)$

In our study, we pooled the curves obtained from the patients at each CRH concentration used. Although pooling of curves could be less sensitive to detect individual variations in the parameters estimated, it ensures a good robustness of the results obtained. Strikingly, excitability (beta) in spontaneous contractions is not less intense in nonpregnant myometrium, and, similarly, the duration of the plateau (theta) is not diminished. Rather, the contrary is observed. Tau 1, representing a subsequent phase of the contraction wave, is also different between pregnant and nonpregnant states, being lower in the latter, suggesting in this case that the curve drops more rapidly (as illustrated theoretically by Fig. 1, bottom). A striking observation is the observed correlation between the size of the plateau (theta) and the drop of the contraction (tau 1) only observed in pregnant myometrium. This correlation is consistent with a better coordination of the muscular fibers near term leading to a more efficient contraction. Indeed, during the final weeks of pregnancy, biochemical and morphological modifications affect the myometrium by promoting the accession of smooth cells toward a highly effective contractile phenotype (5). We observe strong variations of tau 2 among CRH contractions. One possible explication could be the rapid transition of the intracellular compartment from a "sol" to a "gel" state as previously hypothesized (29). Such transition could directly affect the tau 2 parameter and would be more consistent with the high level of released energy during the contraction, hardly compatible with a pure ATP-dependent mechanism.

In conclusion, our work will be pursued at the microscopic level to uncover the structural specificities of pregnant uterus underlying our observations. The curve parameters will be estimated to perform the characterization of uterine response toward various effectors of uterine motility or to evaluate more accurately the modifications of uterine contractions at risk pregnancy such as preterm labor, preeclampsia, and intrauterine growth retardation. In addition, our approach could drive toward external measures around labor, leading to risk evaluation and adequate obstetrical practices.

\section{REFERENCES}

1. Benedetto C, Petraglia F, Marozio L, Chiarolini L, Florio P, Genazzani AR, and Massobrio M. Corticotropin-releasing hormone increases prostaglandin F2 alpha activity on human myometrium in vitro. Am J Obstet Gynecol 171: 126-131, 1994.

2. Berkowitz GS, Lapinski RH, Lockwood CJ, Florio P, BlackmorePrince C, and Petraglia F. Corticotropin-releasing factor and its binding protein: maternal serum levels in term and preterm deliveries. Am J Obstet Gynecol 174: 1477-1483, 1996.

3. Dautzenberg FM and Wille S. Binding differences of human and amphibian corticotropin-releasing factor type $1[\mathrm{CRF}(1)]$ receptors: identification of amino acids mediating high-affinity astressin binding and functional antagonism. Regul Pept 118: 165-173, 2004.

4. Farina LWC. A review of the role of proinflammatory cytokines in labor and noninfectious preterm labor. Biol Res Nurs 6: 230-238, 2005.

5. Ferré F. Molecular mechanism of parturition. Infect Dis Obstet Gynecol 5: 98-105, 1997.

6. Grammatopoulos D, Thompson S, and Hillhouse EW. The human myometrium expresses multiple isoforms of the corticotropin-releasing hormone receptor. J Clin Endocrinol Metab 80: 2388-2393, 1995.

7. Grammatopoulos DK and Hillhouse $\mathbf{E W}$. Activation of protein kinase $C$ by oxytocin inhibits the biological activity of the human myometrial corticotropin-releasing hormone receptor at term. Endocrinology 140: 585-594, 1999.

8. Grammatopoulos DK and Hillhouse EW. Role of corticotropin-releasing hormone in onset of labour. Lancet 354: 1546-1549, 1999.

9. Hillhouse EW, Grammatopoulos D, Milton NG, and Quartero HW. The identification of a human myometrial corticotropin-releasing hormone receptor that increases in affinity during pregnancy. J Clin Endocrinol Metab 76: 736-741, 1993.

10. Hillhouse EW and Grammatopoulos DK. Control of intracellular signaling by corticotrophin-releasing hormone in human myometrium. Front Horm Res 27: 66-74, 2001.

11. Hillhouse EW, Randeva H, Ladds G, and Grammatopoulos D. Corticotropin-releasing hormone receptors. Biochem Soc Trans 30: 428-432, 2002.

12. Karteris E, Hillhouse EW, and Grammatopoulos D. Urocortin II is expressed in human pregnant myometrial cells and regulates myosin light chain phosphorylation: potential role of the type- 2 corticotropin-releasing hormone receptor in the control of myometrial contractility. Endocrinology 145: 890-900, 2004.

13. Li C, Chen P, Vaughan J, Blount A, Chen A, Jamieson PM, Rivier J, Smith MS, and Vale W. Urocortin III is expressed in pancreatic beta-cells and stimulates insulin and glucagon secretion. Endocrinology 144: 32163224, 2003. 
14. Linton EAWJ, Asboth G, Glynn BP, Plested CP, and Bernal AL. Corticotrophin releasing hormone: its potential for a role in human myometrium. Exp Physiol 86: 273-281, 2001.

15. McGrath $\mathbf{S}$ and Smith R. Corticotrophin-releasing hormone and parturition. Clin Endocrinol (Oxf) 55: 593-595, 2001.

16. McLean M, Bisits A, Davies J, Woods R, Lowry P, and Smith R. A placental clock controlling the length of human pregnancy. Nat Med 1: 460-463, 1995.

17. McLean M and Smith R. Corticotrophin-releasing hormone and human parturition. Reproduction 121: 493-501, 2001.

18. Neulen $\mathbf{J}$ and Breckwoldt M. Placental progesterone, prostaglandins and mechanisms leading to initiation of parturition in the human. Exp Clin Endocrinol 102: 195-202, 1994.

19. Papadopoulou N, Chen J, Randeva HS, Levine MA, Hillhouse EW, and Grammatopoulos DK. Protein kinase A-induced negative regulation of the corticotropin-releasing hormone R1alpha receptor-extracellularly regulated kinase signal transduction pathway: the critical role of Ser301 for signaling switch and selectivity. Mol Endocrinol 18: 624-639, 2004.

20. Petraglia F, Benedetto C, Florio P, D'Ambrogio G, Genazzani AD, Marozio L, and Vale W. Effect of corticotropin-releasing factor-binding protein on prostaglandin release from cultured maternal decidua and on contractile activity of human myometrium in vitro. $J$ Clin Endocrinol Metab 80: 3073-3076, 1995.

21. Quartero HW, Noort WA, Fry CH, and Keirse MJ. Role of prostaglandins and leukotrienes in the synergistic effect of oxytocin and corticotropin-releasing hormone $(\mathrm{CRH})$ on the contraction force in human gestational myometrium. Prostaglandins 42: 137-150, 1991.
22. Reis FM, Fadalti M, Florio P, and Petraglia F. Putative role of placental corticotropin-releasing factor in the mechanisms of human parturition. $J$ Soc Gynecol Investig 6: 109-119, 1999.

23. Rodriguez-Linares B, Linton EA, and Phaneuf S. Expression of corticotrophin-releasing hormone receptor mRNA and protein in the human myometrium. J Endocrinol 156: 15-21, 1998.

24. Simpkin JC, Kermani F, Palmer AM, Campa JS, Tribe RM, Linton EA, and Poston L. Effects of corticotrophin releasing hormone on contractile activity of myometrium from pregnant women. $\mathrm{Br} J$ Obstet Gynaecol 106: 439-445, 1999.

25. Singer CA, Salinthone S, Baker KJ, and Gerthoffer WT. Synthesis of immune modulators by smooth muscles. Bioessays 26: 646-655, 2004.

26. Stevens MY, Challis JR, and Lye SJ. Corticotropin-releasing hormone receptor subtype 1 is significantly up-regulated at the time of labor in the human myometrium. J Clin Endocrinol Metab 83: 41074115, 1998.

27. Vale W, Spiess J, Rivier C, and Rivier J. Characterization of a 41residue ovine hypothalamic peptide that stimulates secretion of corticotropin and beta-endorphin. Science 213: 1394-1397, 1981.

28. Vauge C, Carbonne B, Papiernik E, and Ferre F. A mathematical model of uterine dynamics and its application to human parturition. Acta Biotheor 48: 95-105, 2000.

29. Vauge C, Mignot TM, Paris B, Breuiller-Fouche M, Chapron C, Attoui M, and Ferre F. A mathematical model for the spontaneous contractions of the isolated uterine smooth muscle from patients receiving progestin treatment. Acta Biotheor 51: 19-34, 2003.

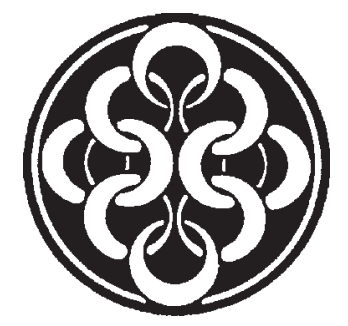

